EDITORIAL

GLÁUCIA MORAES DIAS ${ }^{(1)}$; PATRICIA DUARTE DE OLIVEIRA PAIVA ${ }^{(2)}$

\title{
HOMENAGEM - DR. ANTONIO FERNANDO CAETANO TOMBOLATO
}

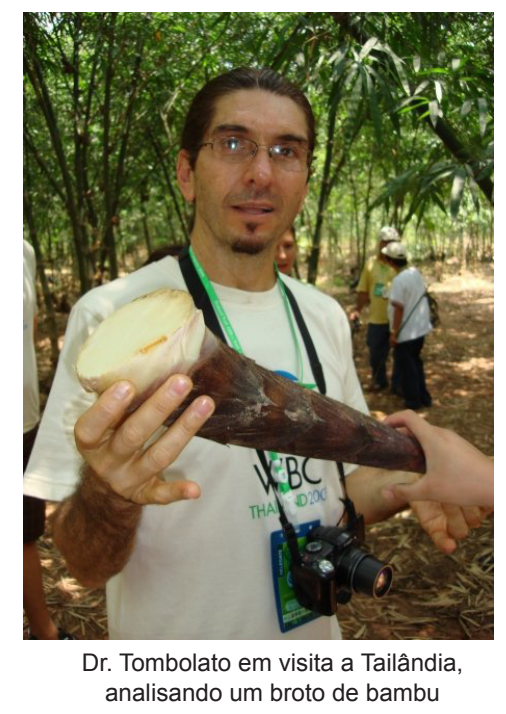

Neste ano de 2015, quando se completam 20 anos de existência da Revista Brasileira de Horticultura Ornamental, nova fase foi inaugurada, adequando-se aos parâmetros de internacionalização e passando a ser denominada Ornamental Horticulture $(\mathrm{OH})$ com novo ISSN-online: 2359-3237, além de DOI em todos os seus artigos. Atualmente a Editoria Científica é exercida pelas editoras Gláucia Dias e Patrícia Paiva, as quais contam com a colaboração do trabalho generoso dos editores de área e de dezenas de destacados pesquisadores envolvidos no processo de avaliação por pares.

A criação da revista se deu em 1995, com intuito de ser um "canal direto entre a pesquisa e o setor produtivo, dinamizando a divulgação dos resultadas das pesquisas cientifica e tecnológica" (Editorial RBHO, v.1 n.1, 1995). Em 2005, numa ação inovadora, o Dr. Fernando Tombolato então editor-chefe, implantou e adotou o sistema online de submissão e trâmite dos trabalhos desta revista. Esse sistema foi utilizado até 2014, quando então precisou ser atualizado com novas tecnologias. Dessa forma, o Dr Tombolato faz parte desta história de sucesso e sempre será lembrado pela sua dedicação, empenho em melhorar a qualidade da revista e inserí-la nesse mundo globalizado

Dr. Fernando Tombolato foi editor chefe da Revista Brasileira de Horticultura Ornamental de 2004 a 2010 e atua como pesquisador científico do Instituto Agronômico de Campinas. A sua formação inclui graduação em Engenharia Agronômica pela Universidade de São Paulo (1977), mestrado em Estudos Aprofundados em Biologia Vegetal pela Université de Bordeaux II (1981) e doutorado em Biologia e Fisiologia Vegetais também pela Université de Bordeaux II (1984). Como pesquisador, possui grande experiência na área de Agronomia, com ênfase em Floricultura, atuando principalmente nos temas: seleção e desenvolvimento de variedades, melhoramento genético, produção de flores e plantas ornamentais. Nos últimos anos vem se dedicando à pesquisa com a cultura do bambu oferecendo subsídios para o cultivo e desenvolvimento dessa cultura inovadora no Brasil. Com quase 200 trabalhos publicados entre artigos científicos, livros, capítulos e boletins, vem contribuído intensamente para introdução de novas cultivares no segmento ainda bastante carente no mercado nacional de plantas ornamentais.

Pela sua contribuição à pesquisa e geração de tecnologias no segmento de floricultura e plantas ornamentais e, sobretudo, pela sua imensurável contribuição à Revista Brasileira de Floricultura e Plantas Ornamentais e também à Sociedade Brasileira de Floricultura e Plantas Ornamentais, é que esse editorial lhe é dedicado.

20 anos - Revista Brasileira de Horticultura Ornamental

\footnotetext{
(1) Instituto Agronômico de Campinas (IAC), Centro de Engenharia e Automação, Jundiaí-SP, Brasil. glaucia@iac.sp.gov.br

(2) Universidade Federal de Lavras (UFLA), Departamento de Agricultura, Lavras-MG, Brasil. presidentesbfpo@gmail.com
} 